Scientia studia, Vol. 1, No. 3, 2003, p. 389-4,04

\title{
st \\ A lição de anatomia de Andreas Vesalius e a ciência moderna
}

Eduardo Henrique Peiruque Kigkhöfel

\author{
Andreas Vesalius de Bruxelas \\ De Humani corporis fabrica, Epitome, Tabulae sex \\ Organização: J. B. de C. M. Saunders e Charles D. O’Malley \\ Tradução: Pedro C. P. Lemos e Maria C. V. Carnevale \\ Ateliê Editorial/Ed. Unicamp/Imprensa Oficial SP, 268 págs.
}

\section{INTRODUÇÃO}

O nome Andreas Vesalius recorda imediatamente o surgimento da anatomia moderna. Nascido em 1514, em Bruxelas, filho de médicos, Vesalius muito cedo voltou-se à medicina. Após estudos em Louvain e Paris, ele foi para Pádua em $15^{3} 7$, cidade cuja universidade o acolheu como explicator chirurgiae, encarregado de ensinar cirurgia e anatomia. Após publicar sua tese de doutoramento, Paraphasis in nonum librum Rhazae ad Regen Almansorum (Paráfrase sobre o nono livro de Rhazes ao rei Almansoro, Louvain e Basiléia, ${ }_{15}^{3} 7$ ), as Tabulae anatomicae sex (Seis pranchas de anatomia, Veneza, 1538), reeditar um texto de seu professor parisiense Johann Guinther von Andernach, Instituitiones anatomicae secundum Galeni sententiam per Ioannen Guntherium Andernachum ab Andrea Vesalio auctiores e emendationes redditae (Procedimentos anatômicos segundo Galeno por Johann Guinther von Andernach com correções e ampliações de Andreas Vesalius, Veneza, 1538), escrever uma carta a respeito da polêmica prática da venissecção, Epistola docens venam axillarem dextri cubiti in dolore laterali secundum (Epistola acerca da veia cúbita auxiliar direita segundo as dores laterais, Basiléia, 1539), e servir como revisor de três textos anatômicos de Galeno para a grande edição Giunta das Opera Galeni (Obras de Galeno, 1541), Vesalius publicou seu grande livro, De humani corporis fabrica (A estrutura do corpo humano, 1543), junto com um resumo intitulado Epitome (Epitome, 1543). Depois disso, Vesalius deixou sua promissora carreira acadêmica e, além da Epistola rationem modumque propinandi radicis Chynae (Epístola sobre a razão e o modo de cura da 
raiz da China, Basiléia, 1546) e uma reedição de $A$ estrutura do corpo humano (1555), seguindo a tradição de sua família, serviu a Casa dos Habsburgos até 1564, ano de sua morte na volta de uma misteriosa peregrinação à Terra Santa. Postumamente, foi editada sua resposta a um texto de Gabriele Falloppio, Observationes anatomicae (Observações anatômicas, Veneza, 1561), acerca de seu grande livro, intitulada Anatomicarum Gabrielis Falloppii observationum examen (Exame das observações anatômicas de Gabriele Faloppio, Veneza, 1564).

Há pouco mais de 50 anos, John Bertrand de Cusance Morant Saunders e Charles Donald O'Malley (1950), autores de uma extensa bibliografia a respeito de história da medicina, na qual se destaca um catálogo a respeito dos desenhos de anatomia de Leonardo da Vinci (1983), publicaram uma edição das ilustrações das publicações de Vesalius, recentemente lançada no Brasil. A edição é composta de um esboço biográfico introdutório seguido de reproduções acompanhadas de traduções de alguns de seus textos e comentários anatômicos detalhados. Seu texto introdutório, que mostra grande conhecimento das fontes por parte dos autores, está ordenado segundo episódios da vida de Vesalius, no qual há seções a respeito de assuntos diversos colocadas em pontos muito oportunos, como por exemplo a discussão a respeito do impressor Johannes Oporinus e do estado da ilustração anatômica na época de Vesalius. Suas opiniões são moderadas a respeito de muitas questões que facilmente provocam especulações sem fundamento, quando não opiniões sensacionalistas, como, por exemplo, a difícil questão da autoria das ilustrações de $A$ estrutura do corpo humano, segundo os próprios autores, já absurdamente consideradas um plágio de desenhos de Leonardo da Vinci.

Entretanto, há ressalvas a apontar a esse texto. Em primeiro lugar, lamenta-se a falta de um aparato crítico para que os leitores busquem as fontes consultadas por Saunders e O'Malley. Segundo os próprios autores (p. 14), a documentação está omitida "por estar além dos objetivos desta publicação". Face a essas palavras, pensa-se a quem se destina o livro. Não obstante sua extraordinária parte ilustrada, cujo subjectum é de interesse amplo e de fácil acesso ao leitor comum, a cultura mediana é evidentemente alheia a uma publicação como essa. O livro em questão não é uma obra de divulgação científica. Mais importante do que isso, para compreender a importância da obra de Andreas Vesalius e, em especial, de seu principal livro, é necessário considerar dois tópicos, quais sejam, o aspecto inovador de suas investigações anatômicas e de sua forma de apresentar o conhecimento anatômico. Ambos tópicos estão mencionados no texto introdutório, mas sem grandes comentários, sendo que o segundo diz respeito diretamente à edição em questão. 


\section{Vesalius inVESTIGADOR DE ANATOMIA}

Falta no texto introdutório um panorama da anatomia e de seu ensino até Vesalius, de modo que a partir disso se possa avaliar a novidade de seus métodos de investigação, a base de sua autoridade. Saunders e O'Malley comentam (p. 21) que "ver um professor descer de sua cátedra acadêmica para dissecar e fazer demonstrações pessoais no cadáver era algo totalmente inusitado na época". A atitude de Vesalius brevemente descrita nessas palavras apenas é entendida quando se sabe que o ensino universitário da anatomia entre o século XIV e a metade do século XVI consistia na leitura de um texto pelo professor para os alunos, geralmente o pequeno e prático Anathomia de Mondino dei Liucci, seguido no século XVI por textos de Galeno, enquanto um assistente, usualmente um cirurgião iletrado, mostrava junto do cadáver as estruturas descritas nesse texto. ${ }^{1}$ Isso está claramente ilustrado em inúmeras gravuras da segunda metade do século XV, como na página-título da edição de Mondino realizada por Martin von Mellerstadt em Leipzig, Anathomia mundini emendata per doctore Melerstrat (Anatomia de Mondino ampliada pelo doutor Mellerstadt, 14,83) [figura 1] e na ilustração que

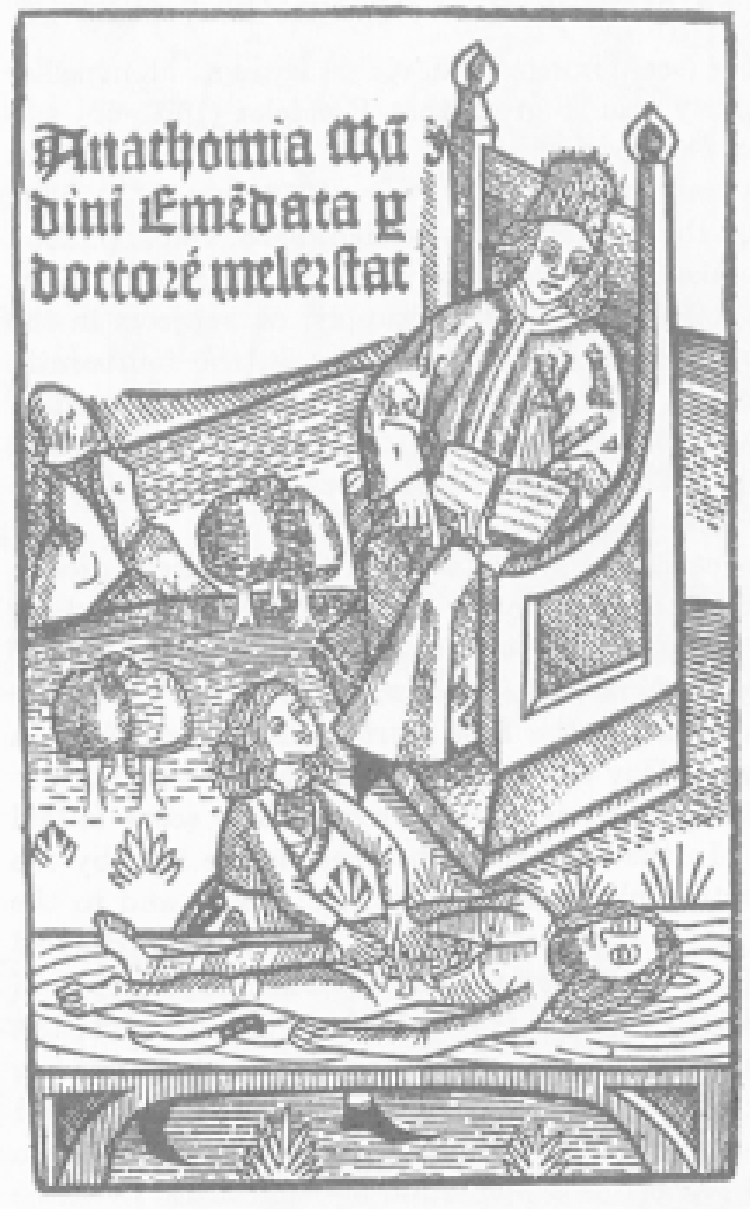

Figura 1: Página-título da edição do comentário de Mondino por Martin von Mellerstadt (Leipzig, 1493).

I A única menção de Saunders e O'Malley nesse sentido, vaga e imprecisa, ocorre após os autores mencionarem os estudos de anatomia realizados em Paris, no porão do Hôtel Dieu (p. 18): "Esses estudos eram feitos à maneira medieval, constituindo-se em pouco mais que formalidades." 
introduz o livro de Johannes de Kethan, Fasciculus medicinae (Fascículo de medicina, 14.91) [figura 2], e mesmo em gravuras do século XVI, como naquela que abre a edição veneziana do comentário de Berengário da Carpi ao texto de Mondino, Carpi Commentaria cum amplissimus additionibus super anatomia Mundini (Comentário de Berengário da Carpi com muitíssimas adições sobre a anatomia de Mondino, 1535) [figura 3]. Fontes textuais também apontam para essa situação. No período em questão, a atividade do professor de anatomia foi expor a tradição textual, como está escrito nos estatutos da Universidade de Pádua: “Como as próprias explicações anatômicas devem seguir Mondino"2 Como aponta Siraisi (1990, p. 89), o objetivo das dissecções conduzidas como parte do treinamento médico era instrução, mas não investigação, de modo que a influ-

Figura 2: Da edição do Fasciculus medicinae de ência textual pôde se fazer presente. $\mathrm{O}$ melhor testemunho disso está em uma parte do prefácio do De humani corporis fabrica, prefácio não traduzido por Saunders e O'Malley. Após comentar a separação entre as formas de cura e o desprezo dos médicos pelas atividades práticas da medicina, Vesalius (1958, p. 522-3) escreve, enfatizando a separação entre o conhecimento dos livros e as técnicas de dissecção:

\begin{abstract}
Mas a perversa distribuição dos instrumentos de cura entre uma variedade de artesãos causou um naufrágio muito mais odioso e um golpe muito mais cruel na principal disciplina da filosofia natural [i.e., a anatomia], à qual, desde que ela compreende a história natural do homem e deve ser corretamente considerada como o firme fundamento da arte da medicina como um todo e seu principal prolegômeno, Hipócrates e Platão deram muita importância e não hesitaram colocá-la como a primeira entre as partes da medicina. Pois embora original-
\end{abstract}




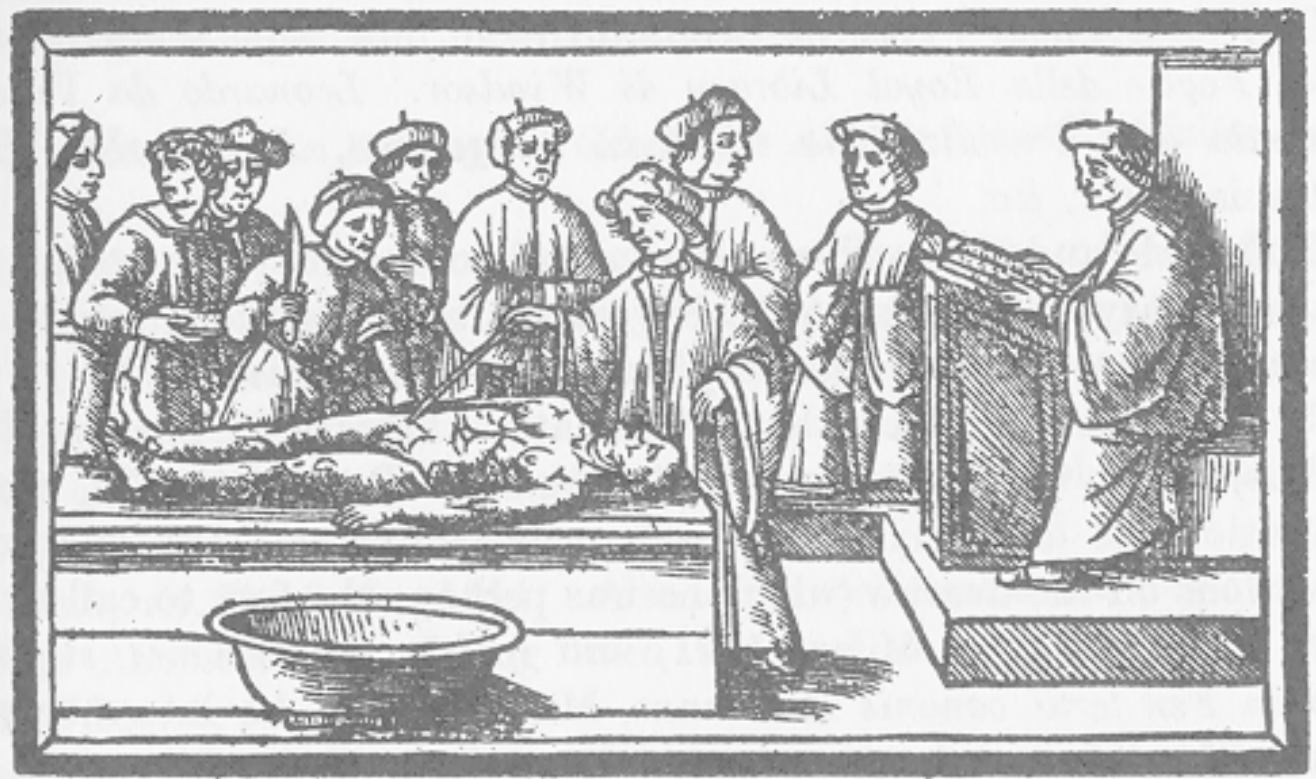

Figura 3: Da edição do comentário do texto de Mondino por Berengário da Carpi (Veneza, $15^{3} 5$ ).

mente a anatomia foi o primeiro objeto dos cuidados dos médicos, e embora eles dissecassem cada nervo para adquiri-la, ela finalmente começou a perecer quando os próprios médicos, delegando as operações manuais a outros, a arruinaram. Pois enquanto os médicos supuseram que apenas os cuidados às enfermidades internas lhes diziam respeito, considerando o mero conhecimento das vísceras mais que o suficiente, eles negligenciaram a estrutura dos ossos e músculos, assim como dos nervos, veias, artérias que correm através dos ossos e músculos, como de nenhuma importância. Além disso, quando toda a condução de operações manuais foi confiada aos cirurgiões-barbeiros, não apenas os médicos perderam o verdadeiro conhecimento das vísceras, mas a prática da dissecção logo morreu, sem dúvida porque os médicos não mais operavam, enquanto aqueles a quem a técnica manual foi confiada eram ignorantes para ler os textos dos professores de anatomia. Era então completamente impossível para essa classe de pessoas preservar para nós a difícil arte que eles haviam adquirido apenas mecanicamente, e igual e inevitavelmente este deplorável desmembramento introduziu em nossas escolas o detestável procedimento hoje em voga, em que um homem faz a dissecação do corpo humano e outro lê a descrição das partes, este último empoleirado sozinho em um púlpito como uma gralha, e com um evidente ar de desprezo ambos despejam informações sobre fatos que nem eles mes- 
mos conhecem em primeira mão, mas meramente buscam de memória de livros de outros, sendo o primeiro tão ignorante em línguas que é incapaz de explicar suas dissecções aos que o observam e remenda o que deveria exibir em acordo com a descrição do médico, que nunca coloca sua mão sobre a dissecação. Assim tudo é ensinado erroneamente, dias são perdidos em questões absurdas e, na confusão, menos é oferecido a um observador do que um açougueiro em seu lugar poderia ensinar um médico.

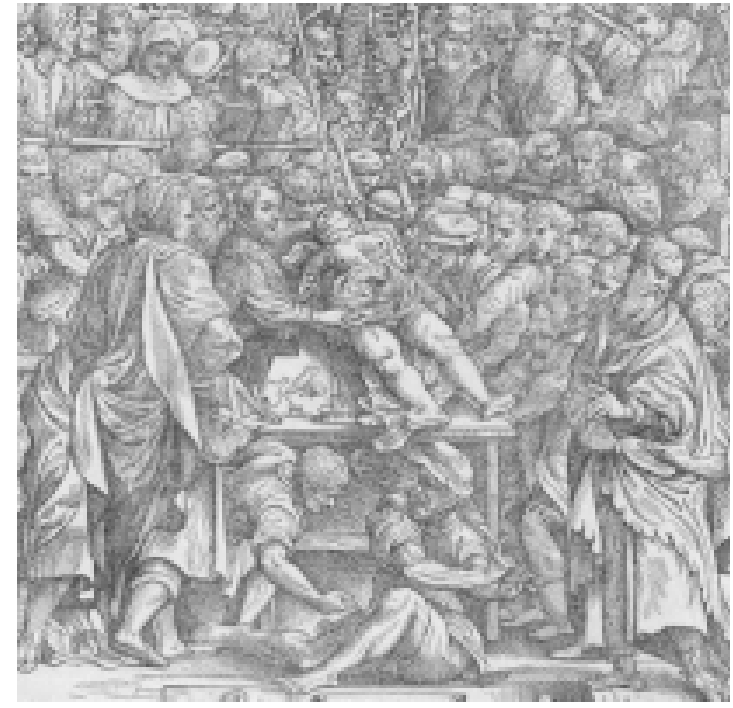

Figura 4: Detalhe do frontispício do De humani corporis fabrica (Basiléia, $154^{3}$ ).

Nesse sentido, entende-se a gravura inicial do De humani corporis fabrica [figura 4], na qual Vesalius está sobre um cadáver demonstrando suas partes, como um contraponto evidente às ilustrações acima referidas.

\section{VESAliUs E A ILUSTRAÇÃo DE ANATOMIA}

Um dos aspectos inovadores do livro de Vesalius é o extenso uso de ilustrações. Como premissa a sua discussão a respeito disso, Saunders e O'Malley comentam (p. 27):

A Renascença viu surgir, no campo da arte, um novo dogma da teoria estética, segundo o qual uma obra de arte é uma representação direta e fiel dos fenômenos naturais. Essa concepção exigia que o artista se familiarizasse com a estrutura e as propriedades físicas dos fenômenos naturais a fim de retratá-las objetivamente e conhecesse as regras da perspectiva e da matemática a fim de obter a exatidão representativa. A Arte tornara-se científica. Nos séculos XV e XVI, a nova teoria estética achava-se totalmente definida e era aceita universalmente; portanto, era perfeitamente lógico que, em seus estudos da natureza, artistas como Andrea del Verrocchio, Andrea Mantegna, Luca Signorelli, Antonio Pollaiuolo, Leonardo da Vinci, Albrecht Dürer, Michelangelo Buonarrotti e Raffaello Sanzio, para mencionar apenas alguns, se dedicassem com entusiasmo ao estudo detalhado do corpo humano. 
Há diversas reservas a fazer a essas palavras. Não havia uma "teoria estética" no Renascimento, mas sim uma série de práticas e textos que nos séculos seguintes foram organizados em maior ou menor grau sob a expressão em questão. De forma rigorosa, pode-se falar de tratados a respeito de artes particulares, mas não de uma "teoria estética", expressão que sugere um conjunto de teses sistematizadas a respeito de uma ou mais artes. A grande variedade de tratados artísticos dos séculos XV e XVI aponta para uma direção oposta a isso. Dificilmente pode-se pensar a respeito de uma concepção de arte "totalmente definida", assim como sua aceitação universal. Considere-se, por exemplo, que Leonardo da Vinci enfatiza em seus escritos a necessidade da anatomia para o pintor, ao passo que Albrecht Dürer, em um de seus livros a respeito das proporções humanas, menciona expressamente que não teve intenções de ensinar a anatomia dos corpos, conforme informa Streider (1996, p. 441); ou considere-se a postura tendenciosa e muito criticada de Giorgio Vasari relativa a valorizar principalmente os artistas florentinos em seu Vite de' piu' Eccellenti Pittori, Scultori e Architettori, Florença, 1568 (Vidas dos mais ilustres pintores, escultores e arquitetos). De modo geral, é possível pensar que existia na Europa - nos Países Baixos e na Itália, em especial - um consenso de opiniões voltado para uma arte de matriz evidentemente naturalista. Além disso, a opinião de que "a arte tornara-se científica" é, a partir da definição de certos termos, insustentável. Um filósofo natural do século XV formalizou sob a forma de discurso seus conhecimentos eruditos relacionados ao mundo dos objetos e fenômenos físicos, conhecimentos eventualmente associados a suas próprias experiências. Um artista do século XV utilizou seus conhecimentos empíricos - eventualmente formalizados sob a forma de desenhos, mas raramente sob a forma de discurso, nunca de forma sistemática - para realizar sua arte específica, seja ela a pintura ou a escultura, entre diversas outras. Entre ambos, existiu uma diferença de objetos e objetivos. Houve aplicações de alguns conhecimentos pertencentes até então ao âmbito da filosofia natural às atividades até então eminentemente práticas e, mesmo assim, em um âmbito restrito. Os estudos de perspectiva dos artistas do Renascimento, por exemplo, foram apenas uma porção de um corpus de conhecimento ótico muito amplo, cujos textos principais foram os de Alhazen, Peckham, Bacon e Pelacano, os quais tiveram por objetivo estabelecer correta e racionalmente as dimensões dos objetos aos olhos dos homens sobre uma superfície pictórica plana. No caso da anatomia, os artistas dos séculos XV e XVI possivelmente assistiram (ou eventualmente realizaram) dissecções. Entretanto, é prudente pensar que eles estudaram muito mais a anatomia superficial do que as dissecções anatômicas propriamente ditas, e que eles pouco se interessaram pela relação entre as formas e as funções do corpo humano. As menções de Giorgio Vasari às disseç̧ões de Antonio del Polaiollo são bem conhecidas, mas não há documentos que sustentem a idéia de que era necessário um artista se familiarizar "com a estrutura e as 
propriedades físicas dos fenômenos naturais a fim de retratá-las objetivamente", excetuando o estranho e complexo caso de Leonardo da Vinci. Nesse sentido, escrever que a "arte tornara-se científica" é incorreto. ${ }^{3}$ Pode-se pensar, no máximo, que algumas artes foram informadas por alguns conhecimentos da ciência da época.

A partir dessas opiniões, Saunders e O'Malley afirmam em seguida que "as ciências naturais modernas devem mais aos esforços desses artistas teorizadores do que a todos comentários abalizados dos médicos sobre os gregos, os médicos medievais e seus intérpretes árabes". 4 Essa opinião diz respeito a considerar o desenvolvimento das ciências naturais modernas principalmente a partir de suas descrições visuais. Não há como negar seu importante papel nesse desenvolvimento. No âmbito vesaliano, Saunders e O'Malley reconheceram isso. Na introdução (p. 13), eles chamam a atenção para o "poder da ilustração quando empregada para o desenvolvimento do conhecimento humano". Pouco depois (p. 21), no comentário às Seis pranchas de anatomia, os autores ressaltam que estudantes, médicos e eruditos enchiam as salas de aula de Vesalius, muitos dos quais, dispostos a refutá-lo, "foram convencidos pela demonstração visual". Após mencionar o uso de "grandes desenhos anatômicos" por parte de Vesalius, Saunders e O'Malley citam o próprio Vesalius (p. 22) a respeito de suas ilustrações: "Não faz muito tempo delineei as veias num quadro. O desenho agradou tanto os professores e todos os estudantes que eles me pediram, veementemente, um desenho igual das artérias e também dos nervos. Eu sabia que desenhos desse tipo seriam de muita utilidade para aqueles que freqüentassem minhas aulas." Além disso, segundo os autores (p. 22), as ilustrações das Seis pranchas de anatomia "estabeleceram um novo critério para o uso da ilustração em biologia". Entretanto, apenas ilustrações não configuram uma ciência, nem mesmo uma ciência descritiva. Não há como desconsiderar o trabalho de sistematização feito pelos filósofos naturais que estudavam a anatomia do corpo humano. O próprio A estrutura do corpo humano é um exemplo disso. Julgá-lo a partir de suas ilustrações apenas, não obstante sua imensa importância, desconsiderando a sistematização de seus conteúdos, é uma estratégia perigosa, como Saunders e O'Malley advertem em sua introdução (p. 13): “O leitor deve, aqui, ser advertido do risco de julgar o conhecimento ou a falta de conhecimento de Vesalius unicamente pelas ilustrações." Além disso, dos artistas citados acima, apenas Leonardo

3 Nessa mesma orientação, os autores (p. 36) escreveram que Vesalius, influenciado pelos ensinamentos humanísticos, buscava a restauração do conhecimento da Antigüidade, e que "esse mesmo impulso motivava os artistas de sua época na busca da natureza”.

4. Mas de forma contraditória a isso, Saunders e O’Malley (p. 13) escreveram que “o estudante de artes gráficas perceberá o movimento que liberou a arte de suas formas convencionais para fazê-la reaproximar-se da natureza", frase que sugere que o livro de Vesalius ensinou o naturalismo aos artistas, quando de fato o naturalismo estava desenvolvido desde o início do século XV, o qual justamente possibilitou a Vesalius realizar sua grande obra. 
da Vinci e Albrecht Dürer foram teorizadores, sendo que os estudos anatômicos de Leonardo ficaram esquecidos durante séculos e Dürer jamais se dedicou à anatomia humana propriamente dita, como mencionado acima.

Isto posto, falta no texto em questão uma discussão acerca da transmissão de conhecimentos através de ilustrações, justamente uma das maiores - senão a maior contribuição de Vesalius à anatomia, ou ao menos a contribuição que diz respeito diretamente a um livro originalmente intitulado "As ilustrações dos trabalhos anatômicos de Andreas Vesalius". Há um panorama histórico da ilustração anatômica no período (p. 27-9), mas os motivos de sua baixa qualidade e da resistência às ilustrações do grande livro de Vesalius por parte de muitos anatomistas de orientação conservadora não estão muito claros. Para entender essas questões, é necessário saber que na época de Vesalius uma cultura visual lentamente iniciava sua formação, a qual diz respeito ao descobrimento de técnicas de ilustração desenvolvidas nos ateliês dos artistas renascentistas e a à intensa atividade editorial da época, que lentamente descobria o "poder da ilustração".

Em primeiro lugar, é importante considerar a separação entre os artistas e os anatomistas até a época de Vesalius. A partir da primeira metade do século XV, nas mãos de artistas como Massacio, Donatello, Pollaiolo, Verrocchio, Michelangelo e Raphael, e artistas teóricos como Alberti e Leonardo, entre muitos outros, a arte européia tomou a direção do naturalismo. Sendo então o homem o centro de todas as perguntas, ou ao menos das perguntas mais importantes, a descrição do corpo humano tomou a posição central nessa busca. Não obstante alguns estudos de anatomia artística feitos pelos artistas mencionados acima, é importante ressaltar que todas as dificuldades de representação da figura humana não se beneficiaram do progresso dos textos anatômicos contemporâneos. Por exemplo, apenas os últimos quatro fólios (a partir do final do fólio 44,r até o fólio 47v) do tratado de Hieronymo Manfredi mencionado adiante estão dedicados à anatomia das extremidades, pois os médicos se interessaram pela anatomia das partes internas do corpo. O próprio Vesalius (1958, p. 522) escreveu sobre o pouco interesse dos médicos que o antecederam pela estrutura dos ossos, músculos, vasos e nervos: "Pois enquanto os médicos supuseram que apenas os cuidados às enfermidades internas lhes diziam respeito, considerando o mero conhecimento das vísceras mais que o suficiente, eles negligenciaram a estrutura dos ossos e músculos, assim como dos nervos, veias, artérias que correm através dos ossos e músculos, como de nenhuma importância." 5 Isso afastou os artistas do conhecimento da

5 Essa observação concorda com Siraisi (1990, p. 85), que menciona que comentadores latinos do Canon de Avicena reduziram a importância de seu conteúdo anatômico com a prática usual de omitir os capítulos a respeito dos ossos, músculos, nervos e artérias de seu Livro 1. 
anatomia médica, pois eles pouco tinham para aprender com os textos então disponíveis. Os artistas resolveram suas dificuldades em seu próprio âmbito, com o desenho e sua prática [figura 5], mas não a partir do conhecimento dos textos sobre anatomia, pois estes não haviam sido escritos para resolver suas dificuldades, mas sim para um público com interesses específicos voltados à philosophia naturalis e à prática médica. Paralelamente a isso, as ilustrações anatômicas em manuscritos e livros no século XV e início do século XVI até Vesalius, excetuando as de Leonardo da Vinci [figuras 6 e 7] , são muito primitivas, como as gravuras dos livros de Berengário da Carpi [figuras 8 e 9]. Não faltavam recursos vindos da arte do desenho, como brevemente descrito acima

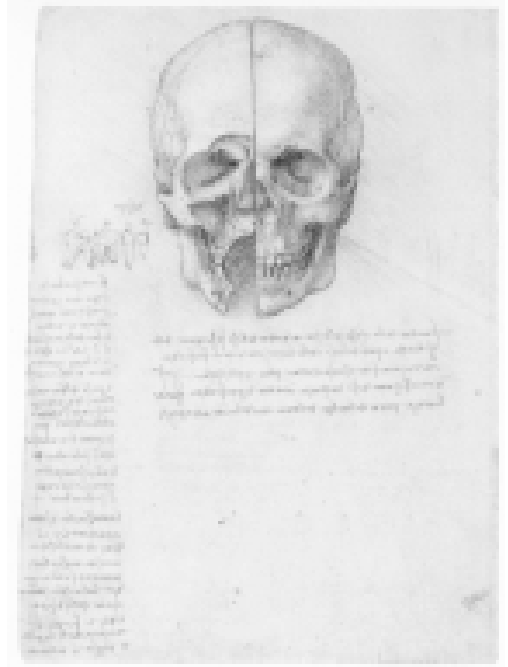

Figura 6: Leonardo da Vinci. $O$ crânio secionado, 1489.

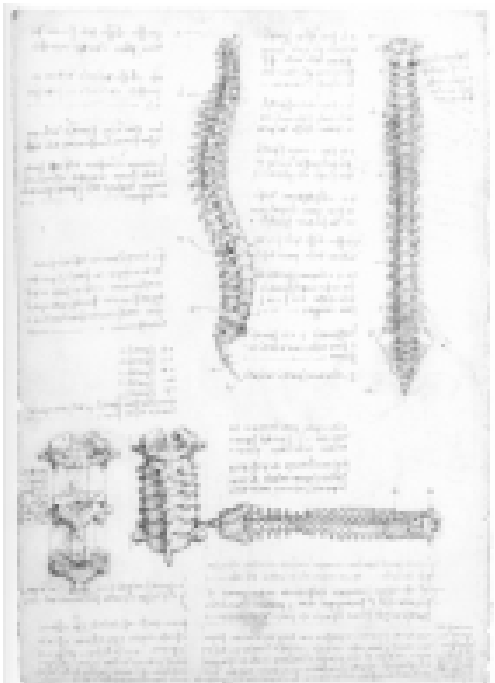

Figura 7: Leonardo da Vinci. Estudos da coluna vertebral, circa 1510 . 


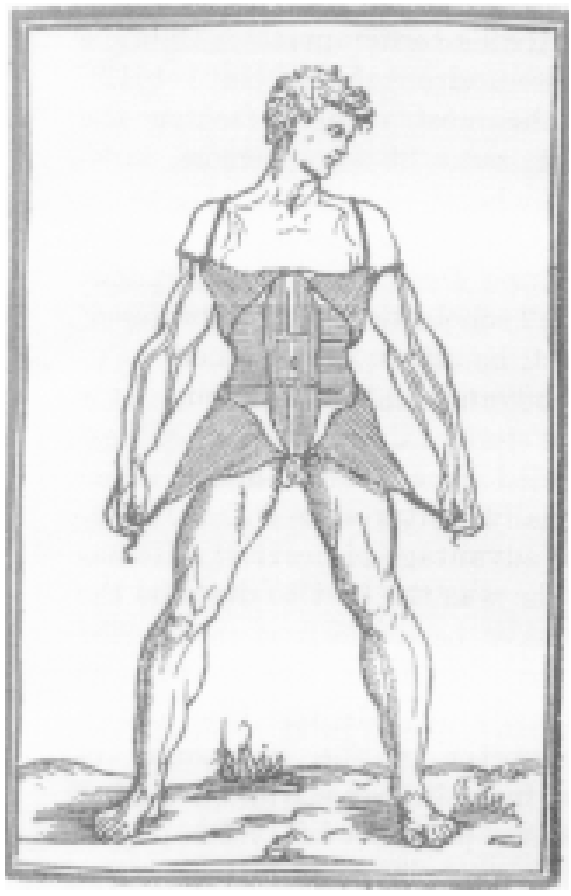

Figura 8: Figura de Isagogae brevis de Berengário da Carpi (Bolonha, ${ }_{5}^{3} 5$ ).

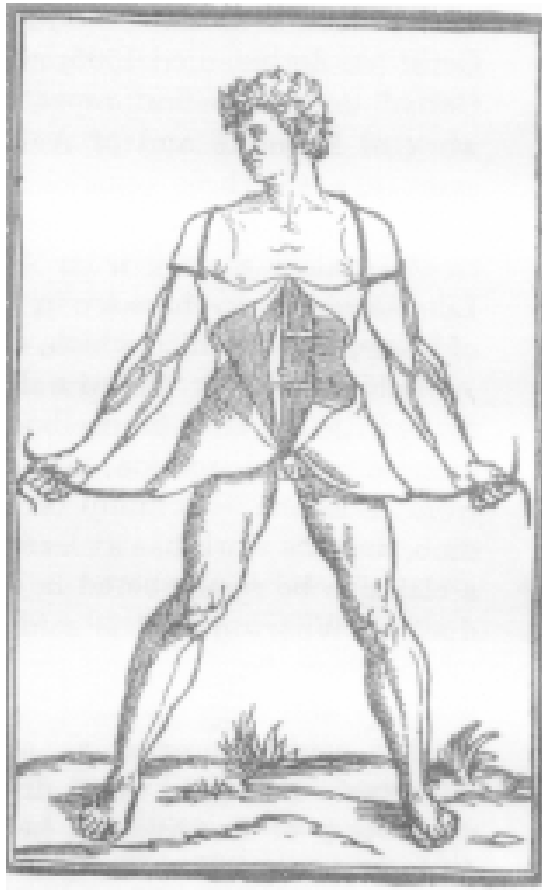

Figura 9: Figura de Isagogae brevis de Berengário da Carpi (Bolonha, ${ }^{3} 5_{5}$ ).

e, nem mesmo, da gravura, ao contrário da afirmação de Saunders e O’Malley (p. 22) acerca da "incapacidade técnica e a falta de evolução dos padrões de reprodução". O excelente nível técnico das gravuras de Andrea Mantegna na Itália e de Albrecht Dürer na Alemanha, entre outros, mostra que havia recursos técnicos para se fazer isso (considera-se aqui apenas gravuras sobre madeira; as gravuras de metal de ambos, em especial as de Dürer, são de um refinamento gráfico que não era possível em livros impressos). As causas da baixa qualidade e da lenta aceitação das ilustrações anatômicas impressas possivelmente estão relacionadas à estrutura do saber acadêmico e às expectativas de seu público. Baseados no ensinamento escolástico textual, devido às fontes da Antigüidade traduzidas pelos humanistas, e certos de que o conhecimento alcançado no passado imediato era muito inferior àquele alcançado na Antigüidade, os comentaristas e professores das universidades e academias tornaram-se muito conservadores em relação aos ensinamentos dos textos antigos, devido às traduções mais rigorosas proporcionadas pelos conhecimentos filológicos dos humanistas. No âmbito da anatomia, como sugerido acima, o limite da profissão do professor de anatomia 
foi expor a tradição textual. O Proemium do texto Anothomia, de Hieronymo Manfredi, escrito circa 1490 e dedicado ao tirano de Bolonha Giovanni Bentivoglio, mostra de forma evidente a dependência da anatomia dos textos antigos: "Pois para esta obra extraí quanto melhor eu pude de vários volumes da Antigüidade e aqui eu os resumi; mas eu não segui a sua ordem, e compus isto como uma obra para o deleite de sua magnificiência." ${ }^{\mathbf{6}}$ Ciência para aqueles homens ainda era principalmente um texto, no qual os sentidos tinham o papel apenas de confirmar as exposições textuais, mas não testálas. É difícil imaginar que um médico nunca tenha pensado utilizar o trabalho de um artista para ilustrar um livro de anatomia. Os artistas desenhavam anatomia nos ospedales e freqüentavam dissecções, e os médicos eventualmente viam seus desenhos, mesmo que apenas de anatomia da superfície do corpo humano. Entretanto, possivelmente a convicção em relação à sua concepção de saber foi mais forte do que algum anseio por inovação. Isto mostra o desinteresse e mesmo a resistência dos médicos pelo trabalho dos artistas à medida que esse podia ser utilizado em seus textos sobre anatomia. De fato, a maior parte das ilustrações anatômicas tinha por objetivo mais fazer seu leitor captar esquemas relacionados à "fisiologia" do que representar naturalisticamente as partes do corpo humano; sua função foi, de certa forma, mnemônica. Comentando as Seis pranchas de anatomia, Saunders e O'Malley (p. 22) consideram a oposição dos anatomistas, mas sua opinião curiosamente não diz respeito ao $A$ estrutura do corpo humano e é limitada: "Muito dos principais médicos da época de Vesalius opunham-se fortemente à ilustração da palavra impressa, sob a alegação de tratar-se de fato inexistente na época dos gregos clássicos por acreditarem que a figura degradaria a erudição do texto.” A carta de Jacobus Sylvius (1478-1553) enviada para o Imperador Carlos V, a quem seu ex-aluno Vesalius servia como médico da corte, é muito clara a esse respeito, embora em 1545 Sylvius lutasse por uma batalha já perdida:

Eu imploro a sua Majestade o Imperador que puna severamente como ele [Vesalius] merece, esse monstro nascido e criado em sua própria casa, esse mais pernicioso exemplar de ignorância, ingratidão e impiedade. [...] Mas se, naquela mistura excessivamente confusa do caluniador, algo apropriado a ser lido é encontrado (pois nenhum escritor é completamente mau), isto é tão pequeno que pode ser acomodado em uma simples folha de papel, considerando que se descarte as ilustrações, as quais são cobertas por sombras e têm letras a elas fixadas. Todo método de empregar essas coisas é decididamente supersticioso e obscuro, e com-

6 Cf. a edição completa desse tratado por Singer (1975). 
pletamente sem uso, e sua Majestade deveria considerar as ilustrações e as letras mais como um impedimento do que uma ajuda. [...] De fato, Galeno não permitiu nem mesmo plantas serem assim descritas no começo do sexto livro, De facul. simp. med. 7

Contrariamente, a posição de Vesalius é muito clara. Após condenar a quase total dependência textual do ensino da anatomia, Vesalius (1958, p. 527-29) relata que certas pessoas o criticavam por colocar ilustrações nos textos anatômicos - possivelmente ele se referia à publicação das Seis pranchas de anatomia - temendo a substituição da realização de dissecções por ilustrações:

Mas aqui vem à minha mente os julgamentos de certos homens que condenam veementemente a prática de colocar diante dos olhos dos estudantes, como nós fazemos com as partes das plantas, desenhos, sendo eles pouco acurados para as partes do corpo humano. Estas, eles dizem, devem ser aprendidas não a partir de desenhos, mas a partir da cuidadosa dissecção e exame das coisas elas mesmas. Como se, em verdade, meu propósito ao adicionar ao texto de meu discurso imagens das partes, que são as mais fiéis, as quais eu desejo que possam estar livres do risco de serem roubadas por impressores, era que os estudantes deveriam confiar nelas e afastar-se da dissecção dos corpos, ao passo que minha prática sempre foi encorajar os estudantes de medicina em todas as maneiras que eu podia para fazer dissecções com suas próprias mãos. [...] Mas quão grandemente os desenhos ajudam no entendimento dessas coisas, e quanto mais acuradamente eles põem as coisas na frente dos olhos do que a mais clara linguagem, como ninguém pode ter falhado de experimentar isso em geometria e outras disciplinas matemáticas.

\section{VESALIUS E A GIÊNGIA MODERNA}

Talvez estas observações sejam mais adições do que críticas ao texto em questão, pois sua orientação evidentemente não é filosófica. Talvez elas pareçam muito severas. Entretanto, sem definir as duas questões apontadas acima, Saunders e O’Malley ficaram sem uma base para pensar a importância de Andreas Vesalius no desenvolvimento da ciência moderna. Mais do que isso, desviando-se de uma definição precisa da ciência 
do período, os autores repetiram insistentemente uma tese não fundamentada. Logo no início (p. 13), eles observam que $A$ estrutura do corpo humano e o texto que o acompanha, Epitome, "estabeleceram, com surpreendente subitaneidade, o início da pesquisa e da ciência moderna com base na observação direta dos fenômenos". Logo depois (p. 14), eles comentam "o repentino surgimento na ciência do método moderno de observação direta dos fenômenos." Mais do que isso, após comentários a respeito do método de Vesalius para resolver o tradicional problema da venissecção (p. 23), eles escrevem que o método de observação direta do corpo humano elaborado por Vesalius fez de $A$ estrutura do corpo humano "o primeiro avanço real na ciência moderna". Em seguida (p. 24), o livro de Vesalius é considerado aquele que "assinala o início da ciência moderna". De forma evidentemente anacrônica, Vesalius (p. 36) é considerado "o epítome do cientista moderno". Por fim, (p. 42), ele é "o primeiro homem da ciência moderna”. Aparentemente, Saunders e O'Malley trabalharam sobre algum conceito de ciência, como mostra sua opinião a respeito de "ocupações intelectuais, científicas ou pseudocientíficas” dos médicos do século XVI (p. 42). Entretanto, isso permanece sem uma definição clara, de modo que a tese apontada acima não está minimamente fundamentada.

A marca distintiva da ciência moderna é a matematização da física associada à experimentação. A matematização da física foi alcançada apenas no início do século XVII por Galileu, em suas análises do movimento dos corpos. A ciência baseada em qualidades de Aristóteles começava a ser substituída por uma ciência baseada em quantidades. Ao lado disso, houve a introdução de experimentos, termo que define um conjunto de procedimentos de investigação controlados e repetíveis, nos quais se pode isolar variáveis de um sistema qualquer, cujo objetivo é algum tipo de análise quantitativa. Ora, a anatomia é uma ciência descritiva. Vesalius, tal qual muitos de seus contemporâneos, observou e descreveu o corpo humano. Não havia como quantificála. Ao lado disso, Vesalius realizou vivissecções, como consta no final do sétimo e último livro de A estrutura do corpo humano, conforme anotado por Saunders e O'Malley (p. 38), e talvez o grau de intervenção e controle sobre o corpo de animais possa ser caracterizado como um experimento, mesmo que incipiente. Entretanto, essa é uma parte menor de seu livro e não sujeita a quantificação, sendo aqui importante lembrar que Vesalius não rompeu com a "fisiologia" de Galeno, como dito por Saunders e O'Malley (p. 19). Dessa forma, a anatomia de Vesalius não satisfaz as condições da ciência moderna. A parte observacional foi importante à anatomia do século XVI, assim como para todas as ciências do século XVII em diante, e a importância de Vesalius nesse ponto é inquestionável. É importante também notar que a dependência de descrições e ilustrações não é uma indicação do estado imaturo de uma ciência descritiva, mas um elemento fundamental em sua estrutura, relacionado à natureza de seu subjec- 
tum. Entretanto, apenas observação e descrição não fizeram a ciência moderna. Nesse sentido, ainda são válidas as seguintes palavras de Alexandre Koyré (1991, p. 294):

De fato, isso [a passagem do mundo do 'mais ou menos' ao universo da precisão] só se aplica às ciências ditas "exatas" (físico-químicas), em oposição à "ciência" ou história qualificada como "natural”; (as ciências que tratam do mundo "natural' de nossa percepção e de nossa vida), que não rejeita - e talvez não o pudesse fazer - a qualidade, para substituir o mundo do "mais ou menos" por um mundo de medidas exatas. Em todo caso, nem na botânica, nem na zoologia, nem mesmo na fisiologia e na biologia, as medidas exatas tiveram um papel a desempenhar; seus conceitos são sempre os conceitos não matemáticos da lógica aristotélica.

Isto posto, resta observar que negar às ciências da vida alguma participação relevante na ciência moderna talvez pareça arrogância. Entretanto, é consenso geral entre historiadores da ciência a importância primeira das ciências "duras" para o desenvolvimento da ciência moderna. Caso se queira contrariar essa tese, que seja apresentada uma nova idéia a respeito da formação da ciência moderna, na qual a obra de Andreas Vesalius seja enquadrada.

\section{A edição brasileira de Vesalius}

A edição brasileira segue o modelo da edição original, sendo apenas um pouco maior, e sua qualidade gráfica é muito boa. Entretanto, pergunta-se por que motivo o título original do livro de Saunders e O'Malley, que descreve corretamente seus conteúdos, foi trocado. Mais importante do que isso, o dorso da edição brasileira é enganoso ("VESALIUS · De HUMANi CORPORIS FABRICA"), pois sugere a edição integral da grande obra de Vesalius. Além disso, falta um prefácio à edição brasileira que a contextualize no âmbito das pesquisas a respeito de Vesalius e sua obra, de modo que se possa pensar sua importância na época de seu lançamento e sua atualidade. De fato, quase vinte anos após a edição em questão, O’Malley (1980) considera a importância de Vesalius para a anatomia moderna sem a menor menção a Vesalius como "o primeiro homem da ciência moderna”. Mesmo com essas reservas, a edição de Vesalius é um lançamento importante no meio acadêmico brasileiro e espera-se que a nova linha editorial a respeito de "Edições Históricas da Medicina", para a qual já estão planejadas edições dos estudos anatômicos de Leonardo da Vinci e William Harvey, conte com o auxílio de historiadores da ciência para que seus novos lançamentos sejam contextualizados em seu respectivos campos de conhecimento. 


\section{Eduardo Henrique Peiruque Kigkhöfel \\ Membro do Projeto Temático \\ "Estudos de filosofia e história da ciência" da FAPESP, doutorando do Departamento de Filosofia da Universidade de São Paulo kickhofel@hotmail.com}

\section{REFERÊNGIAS BIBLIOGRÁFICAS}

GILLISPIE, C. C. (ed.). Dictionary of scientific biography. 14 vols. Nova Iorque, Charles Scribner's Sons, 1980.

KOYRÉ, A. Estudos de história do pensamento científico. Trad. de M. Ramalho. Rio de Janeiro, Forense Universitária, 1991.

OLIVEIRA, A. B. de.Aevolução da medicina. São Paulo, Livraria Pioneira Editora/Secretaria de Estado da Cultura, 1981.

O'MALLEY, G. D. “Andreas Vesalius”. In: GILLISPIE, C. C. (ed.). Dictionary of scientific biography. Vol. 14. Nova Iorque, Charles Scribner's Sons, 1980, p. 3-12.

SAUNDERS, J. B. de C. M. \& O'MALLEY, C. D. The illustrations from the works of Andreas Vesalius of Brussels, with annotations and translations, a discussion of the plates and their background, authorships and influence, and a biographical sketch of Vesalius by J. B. de C. M Saunders and Charles O'Malley. Cleveland/ Nova Iorque, The World Publishing Company, $195^{\circ}$.

. Leonardo on the human body. Translations, text and introduction by Charles D. O'Malley and J. B. de C. M. Saunders. Nova Iorque, Dover, 1983.

SCHWARTZ, G. \& BISHOP, P. W. (eds.). The development of modern science. 2 vols. Nova Iorque, Basic Books, 1958.

SINGER, C. "A study in early Renaissance anatomy, with a new text. The Anothomia of Hieronymo Manfredi (1490)". In: (ed.). Studies in the history and method of science. Vol. I. Nova Iorque, Arno Press, 1975, p. 80-164.

SIRAISI, N. Medieval \& early Renaissance medicine. Chicago/Londres, The University of Chicago Press, 1990.

STREIDER, P. “Albrecht Dürer”. In: TURNER, J. (ed.). The dictionary of art. Vol. 9, Londres, Macmilan, 1996, p. 427-45.

TURNER, J. (ed.). The dictionary of art. 9 vols. Londres, Macmilan, 1996.

VESALIUS, A. "The Preface of Andreas Vesalius to his own books on the anatomy of the human body addressed to The Most Great and Invincible Emperor The Divine Charles V". Trad. de B. Farrington. In: SCHWARTZ, G. \& BISHOP, P. W. (eds.). The development of modern science. Vol. 2. Nova Iorque, Basic Books, 1958, p. 517-32. 